\title{
The Role of External Supports on Performance of Reward Crowdfunding Projects in BRICS Countries
}

\author{
Irma Tsuraya Choirinnida, Liyu Adhi Kasari Sulung*
}

\author{
Department of Management, Universitas Indonesia, Depok, Indonesia \\ ${ }^{*}$ Corresponding author. Email: liyu.as@gmail.com
}

\begin{abstract}
This study analyzes the role of reward and reputation support on the performance of crowdfunding projects in BRICS countries. Ordinary least square is used as methodology research with 582 cross-sectional data from top three creative projects that were conducted on Kickstarter's platform from 2009 to 2019. This research finds that reward and reputation support influence the performance of crowdfunding projects in BRICS countries simultaneously. Egoboosting, customized, and community as variables that explain reward support significantly influence the performance of crowdfunding projects in BRICS countries since the unique products that cannot be obtained by other customers improve backer experience. The number of updates and comments as variables of reputation support significantly influence the performance of crowdfunding projects in BRICS countries because they are useful for giving information to backers and as a communication medium.
\end{abstract}

Keywords: crowdfunding, financing, reward support, reputation support, BRICS countries

\section{INTRODUCTION}

Crowdfunding is a platform that provides alternative financing for high-quality projects from investors with excess funds (Cruz, 2018). A type of crowdfunding that dominates the choice of entrepreneurs nowadays is reward-based crowdfunding (Belleflamme et al., 2013). Reward-based crowdfunding has been a source of small business funding, in exchange for non-monetary rewards for investors such as the company's products, shirts, and even "thank you" (Tonttila, 2016). However, any project that is launched does not directly succeed or, in other words, gain potential investors. Good projects also can fail to gain trust from financial intermediaries, since it is hard to evaluate the entrepreneur's project (Beck \& Demirguc-Kunt, 2006). Therefore, entrepreneurs or creators need to consider effective and efficient campaign strategies to obtain the support of investors or backers. Past research has found the factors that lead to the success of financing both internally and externally in a reward-based crowdfunding campaign. These internal factors relate to the value, creativity, or the usefulness of the final product that is received by the consumer (Gerber \& Hui, 2013). The external support factors relate to the creator's efforts to attract investor trust, which is outside the performance of the final product itself (Bao \& Huang, 2017). In previous studies, there was little discussion about the impact of reward support as external support factors affecting backer's action, even though reward can be an important motivation that encourages backers to participate in the project (Bayus \& Kuppuswamy, 2014). Previous studies also consider combining these external support factors into a new finding and mostly focus on emerging markets. The reason for using BRICS countries is they are commonly used as representatives of emerging countries. Besides, BRICS have a record of rich creative output with the contribution to GDP of 1-6 percent. Comparing to developed economies, the United States has a contribution of 11 percent (Kolisi \& Ncwadi, 2017). Therefore, this study analyzes the impact of external support consisting of reward support and reputation support on performance funding of reward crowdfunding in BRICS.

\section{LITERATURE REVIEW}

\subsection{Reward Support}

A campaign management tool that can be used to encourage investing in a crowdfunding project is reward (Hobbs, Grigore, \& Molesworth, 2016). In general, reward-based crowdfunding offers incentives in the form of pre-sale products, but there are also other types 
of rewards that can be offered by entrepreneurs. Colombo et al. (2015) grouped these into three categories: ego-boosting, customized, and community.

Ego-boosting is a type of reward that lists the backer's name on the site as well as credits in the related projects (Colombo et al., 2015). Ego-boosting is also associated with self-esteem, as one motivations tying people to work and making them more loyal to their work (Romaniuc \& Bazart, 2015). Granting this type of reward could increase the engagement of backers. Gerber and Hui (2013) also found that one of the supporter's motivations to contribute on crowdfunding projects is their desire to engage in activities that create an impact.

Customized reward is a type of reward that entrepreneurs offer in the form of personal goods for backers that cannot be obtained by general customers (Colombo, Franzoni, \& Rossi-Lamastra, 2015). Unlike other types of rewards that are non-monetary, customized rewards are tangible, unusual products such as unique items that have signatures, greetings, and special designs from entrepreneurs (Bao \& Huang, 2017). Somebody can be motivated to do something while his actions give a result for them (Ryu, 2018).

Community reward is another type of reward on a crowdfunding platform which provides an opportunity for backers to interact directly with project makers (Colombo, Franzoni, \& Rossi-Lamastra, 2015). This type of reward allows the backers to share knowledge about hobbies and explore direct experience with entrepreneurs in the creative industry, through workshops, dinner together, or virtual conversations through video calls (Bao \& Huang, 2017). Sunghan and Young-Gul (2016) also identified that a reward that gives pleasure through direct experience can motivate backers to contribute on crowdfunding project. This is related to the desire for supporting others or community belonging as a factor that affects supporters' contribution on crowdfunding project (Gerber \& Hui, 2013). Based on previous research, the following hypotheses are developed:

H1: Reward support described as ego-boost positively influences the performance of crowdfunding's projects in BRICS countries.

H2: Reward support described as customized positively influences the performance of crowdfunding's projects in BRICS countries.

\subsection{Reputation Support}

Campaign quality management can provide a good reputation support to a project (Mollick, 2014). To reach the funding target, an entrepreneur needs to conduct impression management to influence investor trust. Impression management is a person's ability to influence the emotions of other persons through behavior (Mote et al., 2016).

A good impression of a project for supporters can be built through promoting the innovations that entrepreneurs have made for supporters (Lins et al., 2016). An indicator that can be used to promote entrepreneur's innovations is through the use of project updates feature. The feature of updates is one-way communication from entrepreneurs to backers that can inform the status of the campaign (Wang et al., 2018). Crowdfunding, as a platform that gives entrepreneurs the opportunity to gain funding from the public, requires progress-tracking to attract potential investor's trust (Kim et al., 2017). Kim et al. (2017) found that updates play an important role for distributing the information needed by potential investors.

Another form that can be used as a signal of project quality is the size of network described by the number of comments (Mollick, 2014). According to Mollick (2014), a project that has a smaller crowd and attracted fewer investors can be a signal that the entrepreneur potentially has a poor performance. The number of comments signifies if the project is popular so that its credibility can be trusted by investors (Kim et al., 2017). In addition, an interesting project is a project that has a lot of comments, as it signifies the high curiosity of backers (Wang et al., 2018). Comments also can be used as interaction medium between entrepreneurs and the backers, where the backers can convey satisfaction or the performance of the entrepreneur (Wang et al., 2018). Based on the previous research, the following hypothesis is developed:

H2: Reputation support described by updates positively influences the performance of crowdfunding projects in BRICS countries.

\section{RESEARCH METHOD}

This study uses secondary and cross-section data from creative projects in BRICS countries during 20092019. The platform used is Kickstarter and the focus is on the Top 3 launched projects on the platform. The categories are film and video, music, and publication. Kickstarter is the world's largest reward-based crowdfunding platform, and 85 percent of project categories at Kickstarter.com represent creative industry projects.

The sampling method used in this study is purposive sampling, by taking all samples of creative projects in video, music, and publishing categories that have been completed in BRICS, whether successful or not. Then, data cleaning was done for some projects due to outliers. The number of samples used are 96, 69, 162, 140, and 115 for Brazil, Russia, India, China, and South Africa, respectively. 


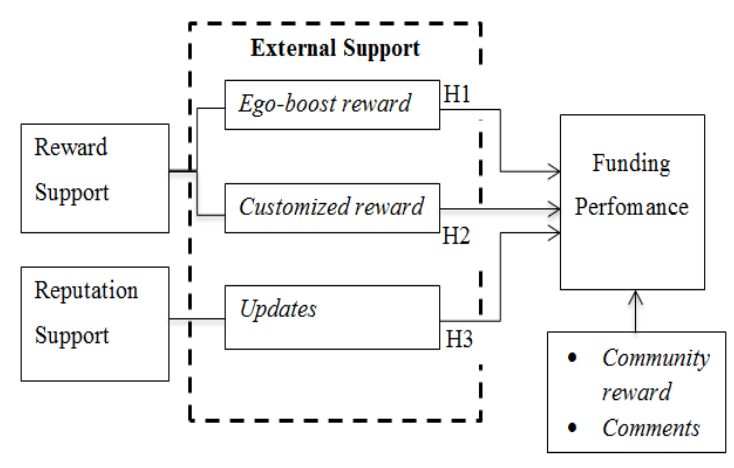

Figure I. Research model.

The collected samples were processed using Microsoft Office Excel program and tested using the Stata 13 program. The research model is shown in figure 1. The project funding performance of the crowdfunding as dependent variable is the ratio of funds that have been reached to the funding target (Bao \& Huang, 2017). The independent variables in the form of reward support are explained by ego-boosting reward, customized reward, and community reward, which are dummy variables (Bao \& Huang, 2017). A value of 1 is given if the project offers a type of ego-boosting, customized, or community in the reward description. The second independent variable is reputation support described by the number of updates and the number of comments on the crowdfunding platform (Kim et al., 2017). This study also uses two control variables: project categories consisting of film and video, music, or publication and the countries where the project launched, namely Brazil, Russia, India, China, or South Africa.

\section{RESEARCH FINDING AND DISCUSSION}

Table 1. Descriptive Statistics

\begin{tabular}{|l|l|l|l|l|l|}
\hline & Mean & Min & Max & SD & Obs \\
\hline $\begin{array}{l}\text { Performance } \\
\text { of funding }\end{array}$ & 0,5327 & 0 & 4,7950 & 0,6061 & 582 \\
\hline Duration & 34,6546 & 2 & 91 & 13,9158 & 582 \\
\hline Goal & 21234,3 & 100 & 1000000 & 59844,82 & 582 \\
\hline $\begin{array}{l}\text { Dummy Ego- } \\
\text { Boosting } \\
\text { Reward }\end{array}$ & 0,7199 & 0 & 1 & 0,4494 & 582 \\
\hline $\begin{array}{l}\text { Dummy } \\
\text { Customized } \\
\text { Reward }\end{array}$ & 0,7835 & 0 & 1 & 0,4122 & 582 \\
\hline $\begin{array}{l}\text { Dummy } \\
\text { Community } \\
\text { Reward }\end{array}$ & 0,5756 & 0 & 1 & 0,4947 & 582 \\
\hline Updates & 4 & 0 & 31 & 6 & 582 \\
\hline Comments & 2 & 0 & 139 & 8 & 582 \\
\hline
\end{tabular}

Based on Table I, we can see that the average funding performance is quite high since the percentage of funding success is above $50 \%$ with an average project funding duration of 35 days. Among 582 collected samples, some projects have no updates and comments. It is shown by the minimum value of updates and the comments as 0 . Meanwhile, the maximum values of updates and comments are 31 and 139, respectively. On average, entrepreneurs post four times and the average comments on the project page is two. Entrepreneurs have on average 1384 Facebook friends with minimum of 9 and maximum of 4981. Obligation, which shows the number of projects that entrepreneurs have previously funded, has an average 2 , with minimum 0 and maximum 60 projects.

This research uses OLS multiple regression method, which needs to test the classical assumptions of multicollinearity and heteroscedasticity. The reason is, if this assumption is violated it will result in an estimate that is not BLUE. According to Brooks (2014), the presence of correlation values between the variables of more than 0.8 and the Mean Variance Inflation Factor (VIF) value of more than 10 can be symptoms of multicollinearity in the model. The research Model is exempt from the multicollinearity problem, as evidenced by the VIF of only 1.17 and the correlation values between the independent variables shown in Table II being less than 0.8. The problem of heteroscedasticity can be eliminated by estimating using OLS regression method and adding robustness (Brooks, 2014). This study also added robustness when the model was estimated, so that the model was free from heteroskedasticity.

Table I1. Correlation Variables

\begin{tabular}{|c|c|c|c|c|c|}
\hline & $\begin{array}{c}\text { Ego- } \\
\text { boosting }\end{array}$ & $\begin{array}{c}\text { Cus- } \\
\text { tomized }\end{array}$ & $\begin{array}{c}\text { Com- } \\
\text { munity }\end{array}$ & $\begin{array}{c}\text { Up- } \\
\text { dates }\end{array}$ & $\begin{array}{c}\text { Com- } \\
\text { ments }\end{array}$ \\
\hline $\begin{array}{c}\text { Ego- } \\
\text { boosting }\end{array}$ & 1,0000 & & & & \\
\hline $\begin{array}{c}\text { Cus- } \\
\text { tomized }\end{array}$ & 0,2389 & 1,0000 & & & \\
\hline $\begin{array}{c}\text { Com- } \\
\text { munity }\end{array}$ & 0,1809 & 0,1721 & 1,0000 & & \\
\hline Updates & 0,1535 & 0,2511 & 0,2478 & 1,0000 & \\
\hline Comments & 0,0822 & 0,0941 & 0,0891 & 0,4099 & 1,0000 \\
\hline
\end{tabular}

In this study, Breusch- Pagan/Cook-Weisberg test was used to detect the presence of heteroscedasticity. $\mathrm{H}_{0}$ in Breusch-Pagan test is a constant variable, with the decision rule rejecting $\mathrm{H}_{0}$ if the value of prob $>\mathrm{chi}^{2}$ is less than $\alpha$ (Verbeek, 2008). Based on the heteroscedasticity test shown in Table III, it can be concluded that the model has heteroscedasticity issue. This is because the value of prob $>\mathrm{chi}^{2}$ is 0.000 , i.e., smaller than $\alpha$, thus $\mathrm{H} 0$ is not accepted. 
Table II1. Breusch-Pagan Test

\begin{tabular}{|l|r|}
\hline \multicolumn{2}{|c|}{ Breusch-Pagan Test } \\
\hline $\operatorname{chi}^{2}(1)$ & 20,74 \\
\hline Prob > chi ${ }^{2}$ & 0,0000 \\
\hline
\end{tabular}

To overcome the problem of heteroscedasticity, according to Brooks (2014), the estimation using the OLS regression method is repeated and then robustness was add. Thus, the research model is homoscedastic, i.e., does not violate the classical assumptions.

The multiple regression results shown in Table IV consist of three models: Model 1 shows the influence of reward support on the performance of project crowdfunding, as described by the ego-boost and customized rewards; Model 2 uses reputation support, as described by variable updates; and Model 3 combines all independent variables of reward support and reputation support.

Table IV. Multiple Regression Results

\begin{tabular}{|c|c|c|c|}
\hline & Model 1 & Model 2 & Model 3 \\
\hline VARIABLES & $\begin{array}{l}\text { (Reward } \\
\text { Support) }\end{array}$ & $\begin{array}{c}\text { (Reputation } \\
\text { Support) }\end{array}$ & $\begin{array}{l}\text { (External } \\
\text { Support) }\end{array}$ \\
\hline \multirow[t]{2}{*}{ Ego-Boost } & 0.0744 & & 0.0005 \\
\hline & $(0.169)$ & & $(0.991)$ \\
\hline \multirow[t]{2}{*}{ Customized } & $0.5127 * * *$ & & $0.3359 * * *$ \\
\hline & (0.000) & & $(0.000)$ \\
\hline \multirow[t]{2}{*}{ Updates } & & $0.0572 * * *$ & $0.0513 * * *$ \\
\hline & & $(0.000)$ & $(0.000)$ \\
\hline \multirow[t]{2}{*}{ Brazil } & -.0245 & $0.1299 * *$ & 0.0834 \\
\hline & $(0.721)$ & $(0.027)$ & $(0.145)$ \\
\hline \multirow[t]{2}{*}{ Russia } & -0.0539 & 0.0672 & 0.0207 \\
\hline & $(0.546)$ & $(0.403)$ & $(0.791)$ \\
\hline \multirow[t]{2}{*}{ India } & -0.0626 & 0.0409 & 0.0211 \\
\hline & $(0.280)$ & $(0.414)$ & $(0.661)$ \\
\hline \multirow[t]{2}{*}{ South Africa } & $-0.178^{*}$ & -0.0477 & -0.0578 \\
\hline & $(0.089)$ & $(0.630)$ & $(0.546)$ \\
\hline \multirow[t]{2}{*}{ Music } & 0.113 & 0.0592 & 0.0701 \\
\hline & $(0.112)$ & $(0.290)$ & $(0.225)$ \\
\hline \multirow[t]{2}{*}{ Publishing } & 0.123 & 0.0855 & 0.0958 \\
\hline & $(0.136)$ & $(0.246)$ & $(0.198)$ \\
\hline \multirow[t]{2}{*}{ Constant } & 0.0770 & $0.246 * * *$ & 0.0231 \\
\hline & $(0.111)$ & $(0.000)$ & $(0.568)$ \\
\hline & & & \\
\hline
\end{tabular}

\begin{tabular}{|l|c|c|c|}
\hline & Model 1 & Model 2 & Model 3 \\
\hline VARIABLES & $\begin{array}{c}\text { (Reward } \\
\text { Support) }\end{array}$ & $\begin{array}{c}\text { (Reputation } \\
\text { Support) }\end{array}$ & $\begin{array}{c}\text { (External } \\
\text { Support) }\end{array}$ \\
\hline Observations & 582 & 582 & 582 \\
\hline R-squared & 0.140 & 0.331 & 0.379 \\
Prob > F & 0.000 & 0.000 & 0.000 \\
\hline
\end{tabular}

The F probability of the whole model is smaller than $\alpha=1 \%$, which means the independent variables of Models 1-4 globally have significant effect on the performance of crowdfunding projects. It is better for entrepreneurs to use the combination of external factors to explain the influence on performance of crowdfunding projects. This can be seen from the result of the goodness of fit test, which shows the ability level of the independent variables in Model 1 to explain the performance of crowdfunding project as 14\%, Model 2 as $33.1 \%$, and Model 3 as $37.9 \%$. The type of external support that entrepreneurs can use to improve project funding performance based on the R-squared value is reputation support.

Based on the results of the individual test on control variables, Model 1 shows a significant negative value for South Africa. This means that China has a higher performance of creative project funding than South Africa. This is because China is one of the most populous emerging market countries. Thus, there are more potential investors from China to support creative projects from their own country and funding performance will be higher. In addition, based on the condition of the crowdfunding platform between these two countries, there are also clearer regulatory guarantees in China than in South Africa. The South African government itself has not set regulations for financial technology, especially crowdfunding. This can affect investor confidence, as they do not like risky investment.

\subsection{The Impact of Reward Support}

The probability of $\mathrm{t}$ value ego-boosting in Models 1 and 3 is greater than $\alpha=10 \%, 0.169$ and 0.991 , respectively. Thus, the ego-boosting reward has no significant effect on the performance of project crowdfunding in BRICS. This hypothesis is not in line with the previous research conducted by Bao and Huang (2017), stating that ego-boosting reward positively influences the performance of crowdfunding projects. However, there are other studies that support this invention, as done by Colombo et al. (2015), who also found that ego-boosting reward has no significant effect on crowdfunding performance. This is because the category of creative projects used here. Film or video, publishing and music categories offer an ego-boost reward that can only be felt by backers at the end of the product. Thus, it does not provide them with more self- 
esteem (Romaniuc \& Bazart, 2015). The probability t value in customized reward is smaller than $\alpha=1 \%$, i.e., 0.000 . The coefficients of $\beta$ from customized reward in Models 1 and 3 are 0.5127 and 0.3359 , respectively. This means that project funding performance will increase when entrepreneurs offer customized rewards. According to Gerber and Hui (2013), the motivation of supporters to fund in crowdfunding projects is to collect rewards that are unique and different from ordinary customers. Customized reward is a form of reward that offers unique gifts because the goods or services cannot be obtained by customers in general.

\subsection{The Impact of Reputation Support}

t-statistical test results show that updates positively influence performance of crowdfunding projects. Models 2 and 4 have probability t value of 0.000 , i.e., smaller than $\alpha=1 \%$, with coefficients of $\beta$ of $5.72 \%$ and $5.13 \%$, respectively. There is a positive influence of number updates on crowdfunding funding performance, in line with previous research conducted by Kim et al. (2017). Updates can be used as communication intermediaries from entrepreneurs to investors and indicate that project are already executed. Through updates, entrepreneurs can post the progress of recent projects. Thus, having more updates available can provide information to backers that the project is run well. Another component in reputation support is number of comments, This was supported by Mollick (2014) who stated that entrepreneur project sites on crowdfunding platforms with few updates will give a signal to investors that the project is inefficient, and entrepreneurs are not serious and have a potential to misuse funds.

\subsection{Robustness Check}

This research added the regressors community as another type of reward support and the number of comments as a form of reputation support in Model 4. The results of the robustness check in Table $\mathrm{V}$ show Models 3 and 4 both have significant global hypothesis test results, where the F probability is less than $\alpha=1 \%$. This signifies that both models have independent variables that can explain the project's funding performance simultaneously. The R-squared value of Model 4 is larger than that of Model 4, meaning that Model 4 has an independent variable that is able to describe the dependent variable $38.8 \%$ better. It can also be seen that the addition of community and comment variables in Model 4 does not change the regression estimation results from the original model, where variables customized reward and updates still have a significant positive effect on the performance of funding crowdfunding reward projects. However, the value of the $\beta$ coefficient for each of these variables decreases in
Model 4. The ego-boosting variable still has no significant effect on the dependent variable.

The results of the individual statistical tests from community reward and comments in Model 4 show that these two independent variables have a significant positive effect on the performance of project funding projects. This can be seen from the probability value $\mathrm{t}$ duration smaller than $\alpha=1 \%$, which is equal to 0.000 . This finding is in line with the research of Bao and Huang (2017), who stated that community rewards have a significant positive effect on the funding performance of crowdfunding projects. Community reward is a type of reward that offers investors experience to interact directly or indirectly with creators (Colombo et al., 2015). This is because investors who interact with creators can directly assess the creator's ability to create and manage projects, so that, when creators campaign on other projects, it will be easy for them to get funding. According to Gerber and Hui (2013), one of the motivations of supporters to spend their money on projects is because they feel part of the community. Comments that explain reputation support also have a significant positive effect on the performance of funding. Comments are used as communication intermediaries between entrepreneurs and backers for questions and answers, and giving criticism and praise for related projects. More comments being received by entrepreneurs indicate that there are also many backers or potential investors who are interested (Wang et al., 2018), especially if comments contain positive feedback. This will also have a positive impact for project's popularity since it provides information for other backers about the quality of the project. Thus, the number of comments can give a signal about the quality of entrepreneurs and crowdfunding projects to investors (Mollick, 2014). 
Table V. Robustness Check

\begin{tabular}{|c|c|c|}
\hline VARIABLES & Model 3 & Model 4 \\
\hline \multirow[t]{2}{*}{ Ego-Boost } & 0.0005 & -0.0152 \\
\hline & $(0.991)$ & $(0.744)$ \\
\hline \multirow[t]{2}{*}{ Customized } & $0.3335 * * *$ & $0.329 * * *$ \\
\hline & $(0.000)$ & $(0.000)$ \\
\hline \multirow[t]{2}{*}{ Community } & & $0.102 * *$ \\
\hline & & $(0.028)$ \\
\hline \multirow[t]{2}{*}{ Updates } & $0.0513 * * *$ & $0.0449 * * *$ \\
\hline & $(0.000)$ & $(0.000)$ \\
\hline \multirow[t]{2}{*}{ Comment } & & $0.00769 * * *$ \\
\hline & & $(0.004)$ \\
\hline \multirow[t]{2}{*}{ Brazil } & 0.0834 & 0.0829 \\
\hline & $(0.144)$ & $(0.136)$ \\
\hline \multirow[t]{2}{*}{ Rusia } & 0.0207 & 0.0323 \\
\hline & $(0.791)$ & $(0.677)$ \\
\hline \multirow{2}{*}{ India } & 0.0211 & 0.0205 \\
\hline & $(0.661)$ & $(0.672)$ \\
\hline \multirow[t]{2}{*}{ SouthAfrica } & -0.0578 & -0.0418 \\
\hline & $(0.546)$ & $(0.662)$ \\
\hline \multirow[t]{2}{*}{ Music } & 0.0701 & 0.0707 \\
\hline & $(0.225)$ & $(0.214)$ \\
\hline \multirow[t]{2}{*}{ Publishing } & 0.0958 & 0.122 \\
\hline & $(0.198)$ & $(0.109)$ \\
\hline \multirow[t]{2}{*}{ Constant } & 0.0231 & -0.0151 \\
\hline & $(0.568)$ & $(0.746)$ \\
\hline Observations & 582 & 582 \\
\hline R-squared & 0.379 & 0.395 \\
\hline Prob $>F$ & 0.000 & 0.000 \\
\hline R-squared & 0.379 & 0.395 \\
\hline Prob $>F$ & 0.000 & 0.000 \\
\hline
\end{tabular}

\section{CONCLUSION}

The reward supports described by ego-boosting, customized, and community have a positive effect on the funding performance of crowdfunding projects simultaneously. However, individual hypothesis test results show ego-boosting reward has no significant positive effect on the dependent variables. The reputation support described by the variables of the updates and comments simultaneously also affects the funding performance of crowdfunding projects in BRICS. This is because the number of updates and comments creates a good impression for the backers about the seriousness of entrepreneurs in managing the project.

The managerial implications of this research are that entrepreneurs should better prioritize the types of customized reward to attract backer's attention and trust. In addition, entrepreneurs can combine reward support, reputation support, and social support to improve the success of their projects. The use of all external support is more effective and efficient than only using one type of external support. Investors can also give a review of any reward or responses to entrepreneurs in the comments field. This is because comments as a reputation support affect project funding performance. By giving reviews, investors have contributed to provide information for other investors and support the potential of success on crowdfunding projects.

\section{REFERENCES}

[1] Bao, Z. and Huang, T. (2017). 'External supports in reward-based crowdfunding campaigns'. Online Information Review, 41(5), pp. 626-642.

[2] Beck, T. and Demirguc-Kunt, A. (2006). 'Small and medium-size enterprises: access to finance as a growth constraint'. Journal of Banking and Finance, 30(11), pp. 2931-2943.

[3] Belleflamme, P., Lambert, T. and Schwienbacher, A. (2013). "“Crowdfunding: Tapping the right crowd" Référence bibliographique Journal of Business Venturing Crowdfunding: Tapping the right crowd $\tau^{2}$. Crowdfunding: Tapping the Right Crowd, 29(5), pp. 585-609.

[4] Brooks, C. 2014 Introductory econometrics for finance (3rd ed). Cambridge University Press, New York.

[5] Colombo, M. G., Franzoni, C. and Rossi-Lamastra, C. (2015). 'Internal social capital and the attraction of early contributions in crowdfunding'. Entrepreneurship Theory and Practice, 39(1), pp. $75-100$.

[6] Cruz, J. V. da (2018). 'Beyond financing: crowdfunding as an informational mechanism'. Journal of Business Venturing, 33(February), pp. 371-393.

[7] Gerber, E. M. and Hui, J. (2013). 'Crowdfunding: motivations and deterrents for participation'. ACM Transactions on Computer-Human Interaction ACM Transactions on computing-human interaction, 20(6), pp. 1-32.

[8] Hobbs, J., Grigore, G. and Molesworth, M. (2016). 'Success in the management of crowdfunding 
projects in the creative industries'. Internet Research, 26(1), pp. 146-166.

[9] Kim, T., Por, M. H. and Yang, S. B. (2017). 'Winning the crowd in online fundraising platforms: the roles of founder and project features'. Electronic Commerce Research and Applications, 25, pp. 86-94.

[10] Kolisi, N. and Ncwadi, R. 2017 Cultural and creaive industries as a catalyst for growth in BRICS economies. Nelson Publishing, Mandela Metropolitan Area Of South Africa's Eastern Cape.

[11] Kuppuswamy, V. and Bayus, B. L. (2014). 'Crowdfunding creative ideas: the dynamics of project backers in Kickstarter'. SSRN Electronic Journal, 34.

[12] Lins, E., Fietkiewicz, K. J. and Lutz, E. 2016 2016-March. 'How to convince the crowd: an impression management approach' Proceedings of the annual Hawaii international conference on system sciences (3505-3514).

[13] Mollick, E. (2014). 'The dynamics of crowdfunding: an exploratory study'. Journal of Business Venturing, 29(1), pp. 1-16.

[14] Mote, G., Vanags, J., Geipele, I. and Bowen, J. 2016 Impression management: impression conceptual definition and model, (November) (149-153). Riga Technical University.
[15] Romaniuc, R. and Bazart, C. 2015 Intrinsic and extrinsic motivation. Encyclopedia of law and economics, 1-4.

[16] Ryu, S. 2018. 'Crwodfunding as a two-sided platform: development of crowdfunding participation model. Institute of Cultural and Creative Industry'. Retrieved from https://papers.ssrn.com/sol3/papers.cfm?abstract_id $=2423315$.

[17] Ryu, S. and Kim, Y. (2016). 'A typology of crowdfunding sponsors: birds of a feather flock together?' Electronic Commerce Research and Applications, 16, pp. 43-54.

[18] Tonttila, J. 2016. 'Reward-Based Crowdfunding Case ASMO-charger'. Retrieved from https://www.theseus.fi/bitstream/handle/10024/104 744/Tonttila_Juho.pdf?sequence=1. Oulu University of Applied Science (1-36).

[19] Verbeek, M. 2008. 'A guide to modern econometrics'. Retrieved from https://books.google.co.id/books?id=uEFm6pAJZh oC\&pg=PA99\&dq=\%22breusch+pagan+test $\% 22 \&$ hl=id\&sa=X\&ved=0ahUKEwitjIystPfhAhUYaI8K HUrhBf0Q6AEILDAA\#v=onepage \&q=\%22breusc $\mathrm{h}$ pagan test $\% 22 \& \mathrm{f}=$ false.

[20] Wang, N., Li, Q., Liang, H., Ye, T. and Ge, S. (2018). 'Understanding the importance of interaction between creators and backers in crowdfunding success'. Electronic Commerce Research and Applications, 27, pp. 106-117. 